\title{
Spontaneous Heterotopic Triplet Pregnancy with a Two Viable Intrauterine Embryos and an Ectopic One with Right Tubal Rupture
}

\section{Gravidez heterópica tripla espontânea com dois embriões intrauterinos viáveis e um ectópico com ruptura da tuba uterina direita}

\author{
Adriano Carvalho Guimarães ${ }^{10}$ Luciano Dias de Oliveira Reis ${ }^{2}$ Fabio Chaves Leite ${ }^{3}$ \\ Cassiana Franco Dias dos Reis ${ }^{2}$ Alex Paula Costa ${ }^{2}$ Walter Junior Boim de Araujo ${ }^{4}$
}

1 V\&P Health Excelência Médica, Santo Antônio da Platina, PR, Brazil

${ }^{2}$ Hospital Nossa Senhora da Saúde, Santo Antônio da Platina, PR, Brazil

Address for correspondence Adriano Carvalho Guimarães, Av. Frei

${ }^{3}$ Hospital Regional do Norte Pioneiro, Santo Antônio da Platina, PR, Brazil Guilherme Maria, 627, Jardim Egea, Santo Antônio da Platina, PR,

${ }^{4}$ Instituto da Circulação, Curitiba, PR, Brazil

Rev Bras Ginecol Obstet 2019;41:268-272.

Abstract
Keywords
- obstetrical surgery
- pregnancy
complications
- heterotopic
pregnancy
- multiple pregnancy
- tubal pregnancy
Resumo


Palavras-chave
- cirurgia obstétrica
- complicações na
gravidez
- gravidez heterotópica
- gravidez múltipla
- gravidez tubária

Heterotopic pregnancy (HP) is defined as the simultaneous development of an intra- and an extra uterine gestation. The occurrence of a spontaneous triplet $\mathrm{HP}$ is an exceptionally rare medical condition. We report the case of a young woman with spontaneous heterotopic triplets at 8 weeks of gestation, with a misdiagnosis of topic twins and acute appendicitis. The ectopic tubal pregnancy was ruptured and a salpingectomy was performed by laparotomy. The intrauterine pregnancy progressed uneventfully. The two healthy babies were delivery by cesarean section at $36 \pm 2$ weeks of gestation. Heterotopic triplets with ruptured tubal ectopic pregnancy represent a special diagnostic and therapeutic challenge for the obstetrician. A high rate of clinical suspicion and timely treatment by laparotomy or laparoscopy can preserve the intrauterine gestation with a successful outcome of the pregnancy.

A gravidez heterotópica é definida como o desenvolvimento simultâneo de uma gestação intra- e extra-uterina. A ocorrência de gravidez tripla heterotópica espontânea é uma condição médica excepcionalmente rara. Relatamos o caso de uma jovem com gravidez tripla espontânea, às 8 semanas de gestação, com um diagnóstico errôneo de gêmeos tópicos e apendicite aguda. A gravidez tubária ectópica estava rota e uma salpingectomia foi realizada por laparotomia. A gravidez intrauterina progrediu sem intercorrências. Os bebês nasceram saudáveis por cesariana realizada às 36 semanas de gestação. A gravidez de heterotópicos com ectopia e rotura tubária é um desafio diagnóstico e terapêutico. Um alto índice de suspeita e tratamento oportuno por laparotomia ou laparoscopia podem preservar a gestação intrauterina com um resultado bem sucedido da gravidez tópica.

(1DAdriano Carvalho Guimarães's ORCID is https://orcid.org/00000002-0547-5596.

received

April 24, 2018

accepted

February 8, 2019
DOI https://doi.org/

10.1055/s-0039-1683910. ISSN 0100-7203.
Copyright (e) 2019 by Thieme Revinter

Publicações Ltda, Rio de Janeiro, Brazil
License terms

(c) (1) 


\section{Introduction}

Heterotopic pregnancy (HP) is a rare medical condition in obstetrics. It is characterized by the presence of coexistent intrauterine and ectopic pregnancies. The most frequent implantation site of the ectopic pregnancy is the fallopian tube, most commonly in its ampullary segment (80\%)., The incidence of HP is around 1:30,000, in spontaneous pregnancies. $^{1-3}$ In pregnancies resulting from assisted reproduction techniques (ART), the incidence is greater, ranging from $1: 100$ to $1: 3,600$, nearly as high as $1 \%$ in some series. ${ }^{1,2}$ Overall, the incidence of HP nowadays is estimated around $1: 7,000^{2}$ to $1: 15,000$ live births (0/8\% calculated risk) in contrast with the lower incidence of $1: 30,000$ in $1948 .{ }^{4}$ The higher incidence of HP in patients under ARTs programs is attributed to multiple ovulation, higher incidence of pelvic inflammatory disease (PID) observed currently, and tubal damage related or not to transfer of many embryos. ${ }^{1,5}$ The twin rate increased from $1.8 \%$ in $1971-77$ to $2.8 \%$ in 1998 , attributable to ART extended use. ${ }^{6}$ Heterotopic triplets are even more uncommon, and cases with tubal ectopic and coexisting twin intrauterine pregnancy are limited. This medical condition can be hazardous to the intrauterine pregnancy as well as to the life of the mother. We present the case of a ruptured right tubal pregnancy, referred as acute abdomen in a patient pregnant with intrauterine twins and suspected acute appendicitis. The final outcome was the birth of healthy twins. The aim of this paper is to emphasize the need for high clinical suspicion of this clinical entity during the routine first trimester ultrasound examination, even in the presence of an intrauterine multiple gestation and especially when predisposing factors such as in vitro fertilization (IVF) are present.

\section{Case Description}

A 21-year-old woman, primigravida, with a confirmed intrauterine twin pregnancy, was referred to the emergency department of our hospital by her family doctor, presenting with abdominal pain in the right iliac fossa, with diagnosis of acute appendicitis, on April 25, 2017 at 8 PM. On admission, she was stable, with a normal level of consciousness. The pulse rate of the patient was $97 / \mathrm{min}$, and her blood pressure was $100 / 60 \mathrm{mmHg}$. The level of hemoglobin was $8.5 \mathrm{~g} / \mathrm{dl}$ and leukocytosis was observed (23.700/uL). An ultrasonography had shown a 2-cm tubular structure in the right iliac fossa, reported as acute appendicitis, and an 8 -week viable intrauterine twin gestation (-Figs. 1A, 1B, 1C).

Physical examination demonstrated marked right iliac fossa tenderness and rebound. After examination by the surgeon on call, the patient was immediately sent to the operating room and underwent an emergency laparotomy, via Mcburney incision, during which an organized hematoma was encountered. A normal appendix was found and a midline infra umbilical second incision performed. A ruptured right ectopic pregnancy was confirmed, and a right salpingectomy was performed (-Fig. 2).
The postoperative recovery was uneventful, and the patient was discharged on the third day. A transvaginal ultrasonography on the second postoperative day showed viable topic twins with crown-rump length measurements of 17 and $17.2 \mathrm{~mm}$, compatible with an $8 \pm 1$ weeks pregnancy. Histopathological examination confirmed the diagnosis of ectopic tubal pregnancy. The obstetric follow-up and fetal assessments were normal, with normal fetal growth of each twin until the $24^{\text {th }}$ week. The intrauterine babies were born healthy by cesarean section at 36 weeks of gestation.

\section{Discussion}

Heterotopic triplets are rarely encountered in everyday clinical practice. However, the extended use of ART procedures nowadays has increased the ectopic and, subsequently, the HP rates. This clinical entity represents a potentially lifethreatening condition for both the mother and the intrauterine pregnancy ${ }^{2}$ and was first reported by Marshal in $1903 .^{7}$ Predisposing factors to HP are identical to those predisposing to ectopic pregnancy: factors related to IVF, like large number of transferred embryos, a transfer near the uterine horn, excessive pressure on the syringe and deep insertion of the catheter during transfer, the quality of the embryos, the hormonal milieu at the moment of transfer, the use of gonadotropins, the amount of fluid used as media for the embryos, and also adhesions related or not to endometriosis and PID. ${ }^{8,9}$ In our case, the patient had no history of PID or infertility. She was pregnant for the first time, resulting in low suspicion of HP.

The implantation of an embryo in the wall of the fallopian tube bears a high risk of rupture because the rich local vascularization and trophoblastic invasion may cause tubal rupture, even if there is no fetal cardiac activity. In cases of HP following IVF, the diagnosis can be exceptionally difficult. The Beta-human chorionic gonadotropin ( $\beta$-hCG) may continue to rise normally, the ovaries may present enlarged, the ectopic gestational sac can easily be missed on ultrasound scan, and the intermittent unilateral pain can be attributed to a hemorrhagic corpus luteum or ovarian hyper stimulation. ${ }^{10}$ It is reported that approximately $70 \%$ of heterotopic pregnancies are diagnosed between 5 and 8 weeks of gestation, 20\% are diagnosed between 9 and 10 weeks, and the remaining $10 \%$ are diagnosed after 11 weeks. ${ }^{11}$ Only in $57 \%$ of the cases presented in the literature the diagnosis of heterotopic triplets was preoperatively made. ${ }^{11}$ Around $50 \%$ of heterotopic pregnancies are asymptomatic. ${ }^{3}$ Most of them (78.5\%) were diagnosed after the rupture of the tube, with acute abdomen symptoms. ${ }^{5}$ Abdominal pain due to peritoneal irritation is the most frequent symptom appearing in $82.7 \%$ of heterotopic pregnancies. Cases of heterotopic triplets with bilateral tubal pregnancy and an intrauterine pregnancy have been reported in the literature, and symptoms may, in such cases, diffuse abdominal pain. ${ }^{12}$ We identified a total of 11 cases of spontaneous HP, 6 of which were included in the review by Bataille et $\mathrm{al}^{13}$ as shown in -Table 1 below. The most common symptom was low abdominal pain, the most commonly diagnosed method was 


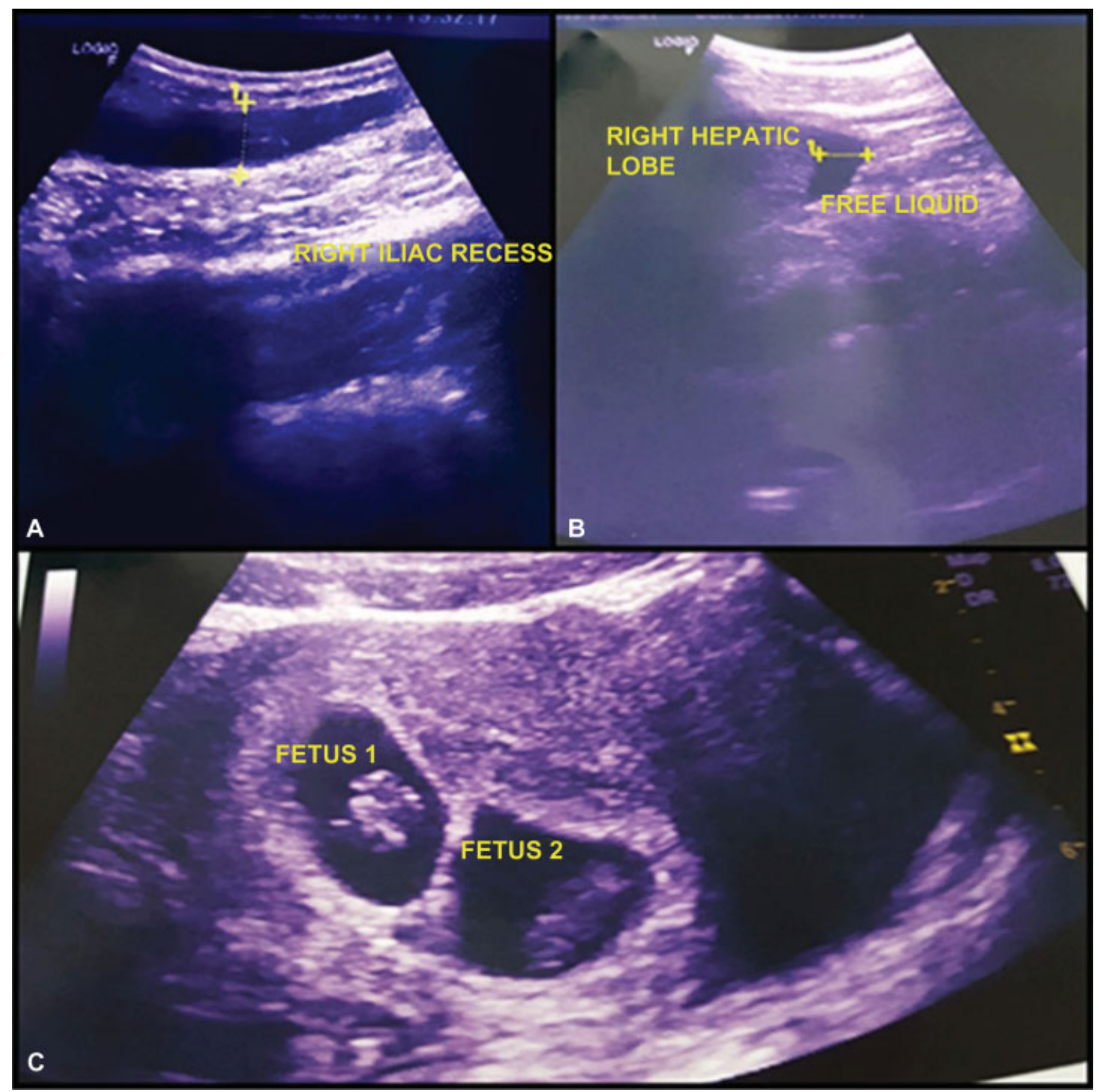

Fig. 1 An ultrasonography had shown a 2 centimeters tubular structure in the right iliac fossa reported as acute appendicitis (A), presence of fluid in the perihepatic space (B), and 8-week viable intrauterine twin gestation (C).

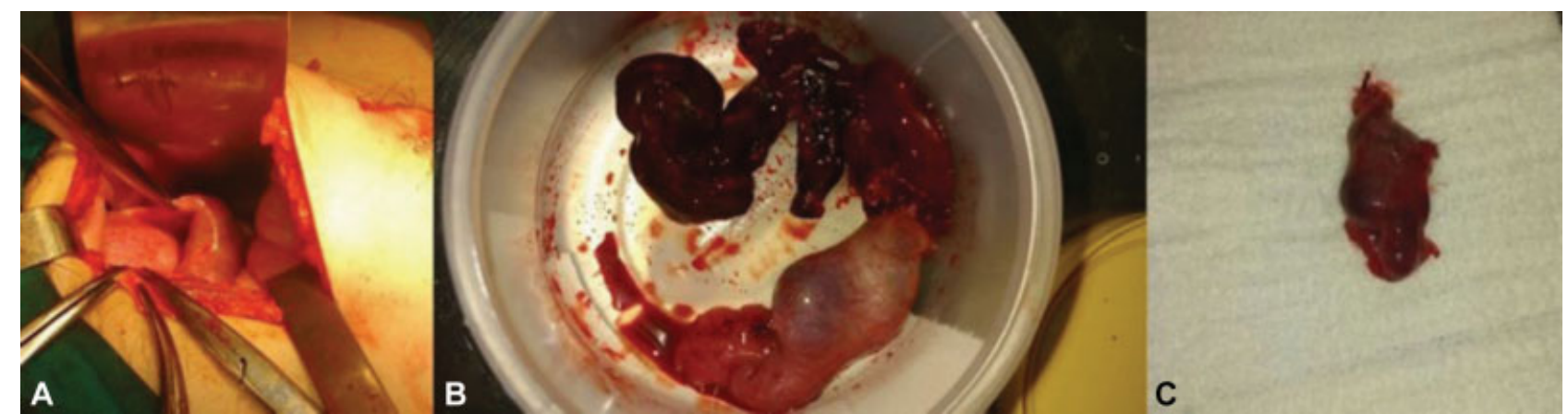

Fig. 2 Intraoperative image of right uterine tube (A). Anatomical specimen of right uterine tube with ectopic fetus (B and C).

ultrasonography, and the most widely adopted surgical procedure was laparotomy with salpingectomy. Yet, of all cases evaluated, only10 resulted in the baby being born alive and healthy.

All the cited literature are reports of unique cases.
The diagnosis should not be missed in cases of pregnant women with abdominal pain due to peritoneal irritation, even when they are referred with the diagnosis of possible appendicitis as in our case. The purpose of the treatment is to interrupt the development of the ectopic pregnancy and 


\begin{tabular}{|c|c|c|c|c|c|c|c|c|c|c|c|}
\hline 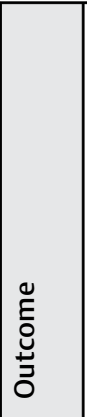 & 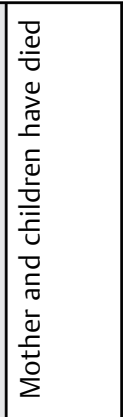 & 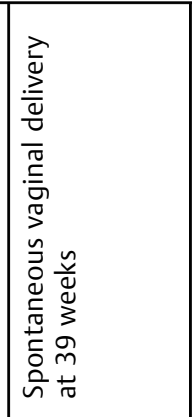 & 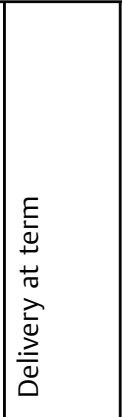 & 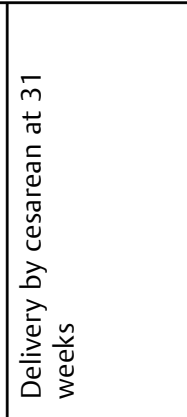 & 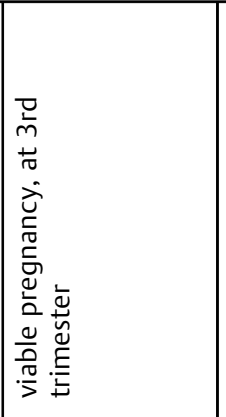 & 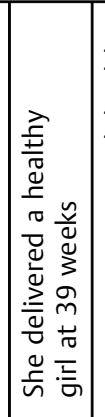 & 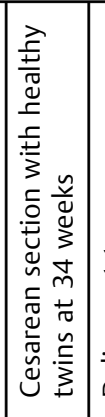 & 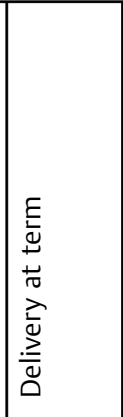 & 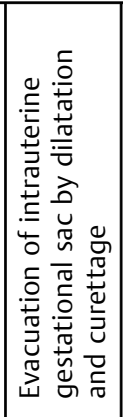 & 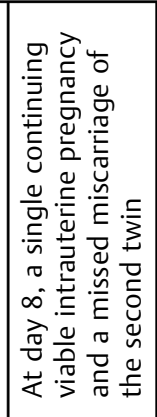 & 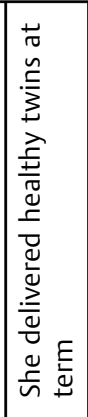 \\
\hline 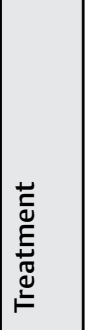 & 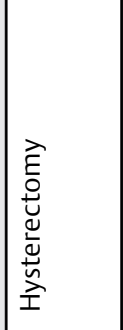 & 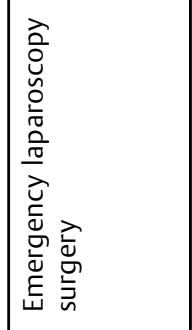 & 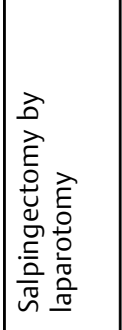 & 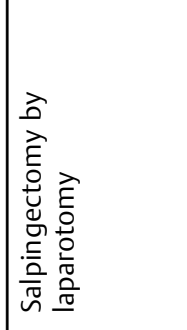 & 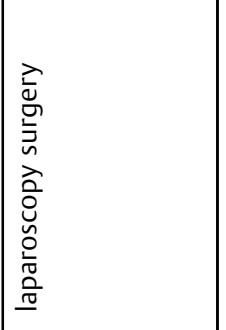 & 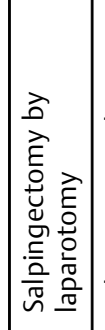 & 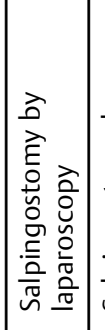 & 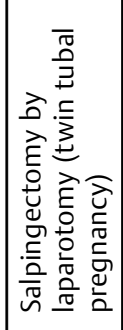 & 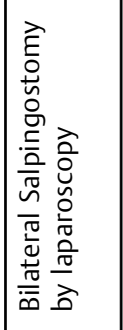 & 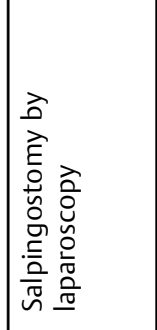 & 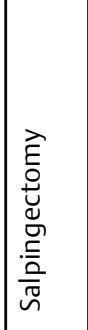 \\
\hline 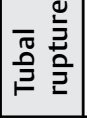 & $\stackrel{\Xi}{\supset}$ & $\stackrel{\check{\nu}}{\nu}$ & 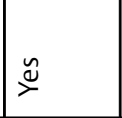 & z & $\stackrel{\ddot{\nu}}{\rightleftharpoons}$ & $\stackrel{\check{y}}{\rightleftharpoons}$ & $\stackrel{\check{y}}{\nu}$ & 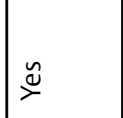 & $\stackrel{y}{\nu}$ & $\stackrel{\check{\nu}}{\nu}$ & r. \\
\hline 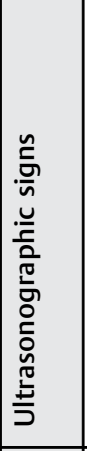 & & 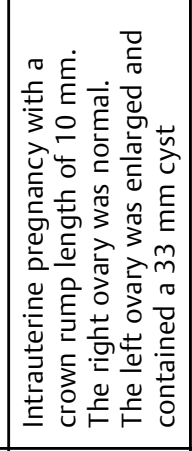 & 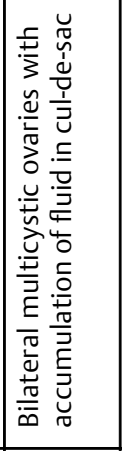 & 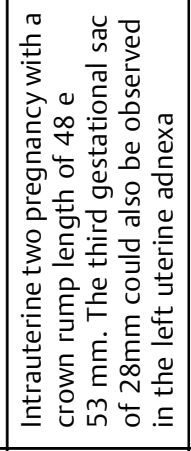 & 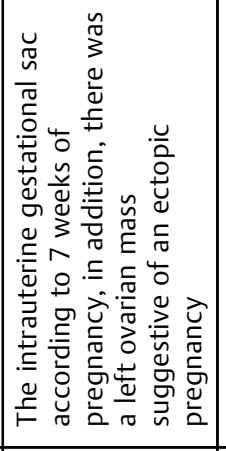 & 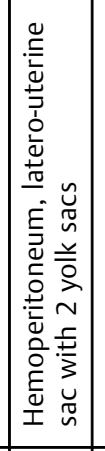 & 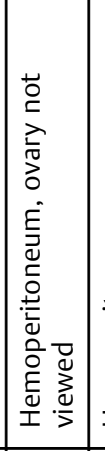 & 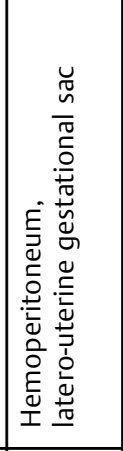 & 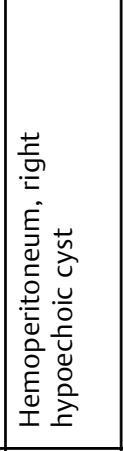 & 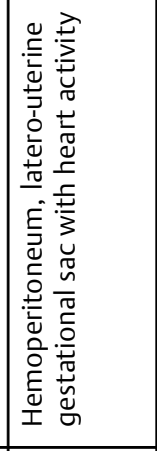 & 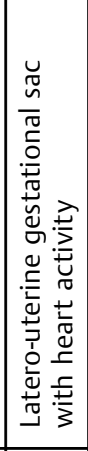 \\
\hline 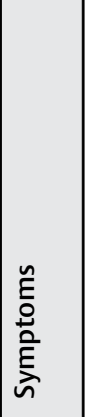 & 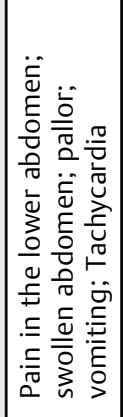 & 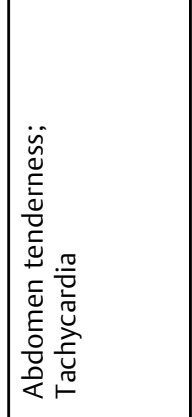 & 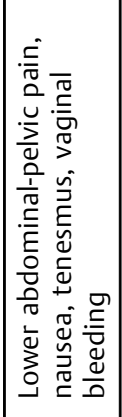 & 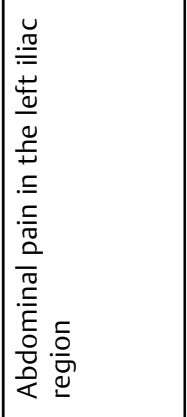 & 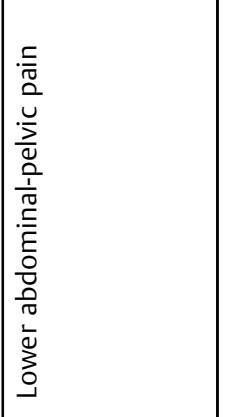 & 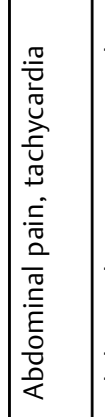 & 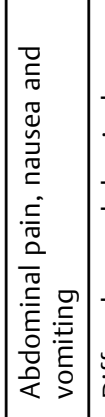 & 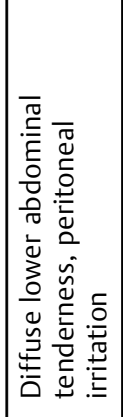 & 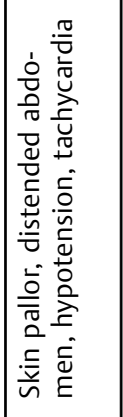 & 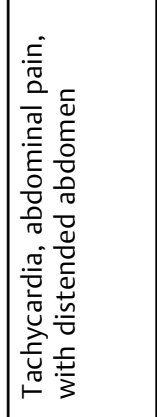 & r. \\
\hline 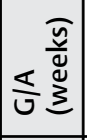 & 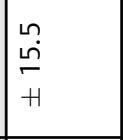 & $\wedge$ & in & $\simeq$ & $\wedge$ & $\infty$ & $\mid \begin{array}{l}n \\
n\end{array}$ & $\sigma$ & 0 & 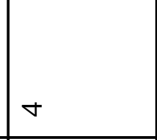 & . \\
\hline 幽: & i & $\lesssim$ & $\stackrel{\infty}{m}$ & $\stackrel{\infty}{\sim}$ & $\stackrel{\infty}{\sim}$ & f & m & $\hat{m}$ & 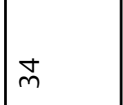 & 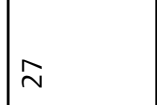 & r. \\
\hline 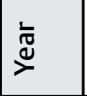 & 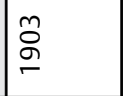 & 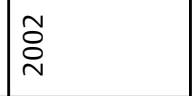 & ڤे & 产 & 弪 & 㖞 & 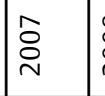 & 离 & 啇 & 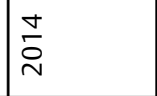 & 啇 \\
\hline $\begin{array}{l}\frac{n}{0} \\
\frac{c}{3} \\
\frac{1}{\alpha}\end{array}$ & 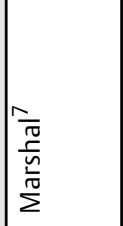 & 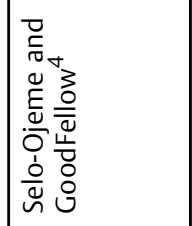 & 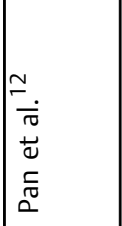 & 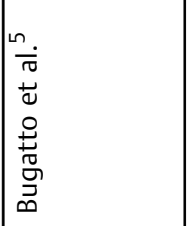 & 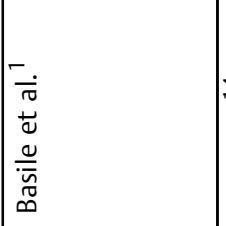 & 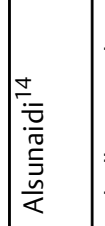 & 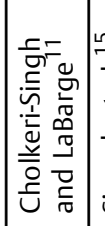 & 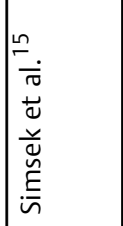 & 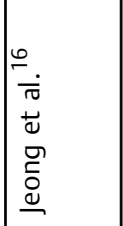 & 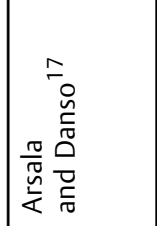 & 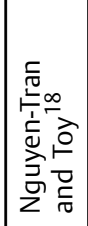 \\
\hline
\end{tabular}


preserve the intrauterine pregnancy. Most cases of HP with tubal pregnancy have been treated surgically. The prognosis of the intrauterine gestation after treatment of the ectopic pregnancy is good. We observed high birth rates in this review above $90 \%(10 / 11)$.

\section{Conclusion}

As a conclusion, it is important to emphasize the need for systematic exploration of the pelvis upon the first ultrasound scan of the pregnancy performed between 7 and 8 weeks of gestation, even if an intrauterine gestational sac is already confirmed, and even if there is no apparent risk factor. It is a fact that the diagnosis of HP tends to be overlooked after confirming the intrauterine pregnancy. When a diagnosis is established on time, the rate of pregnancies that reach term after treatment is significant.

\section{Conflicts of Interest}

The authors have no conflicts of interest to declare.

\section{References}

1 Basile F, Di Cesare C, Quagliozzi L, et al. Spontaneous heterotopic pregnancy, simultaneous ovarian, and intrauterine: a case report. Case Rep Obstet Gynecol 2012;2012:509694. Doi: 10.1155/2012/ 509694

2 Felekis T, Akrivis C, Tsirkas P, Korkontzelos I. Heterotopic triplet pregnancy after in vitro fertilization with favorable outcome of the intrauterine twin pregnancy subsequent to surgical treatment of the tubal pregnancy. Case Rep Obstet Gynecol 2014; 2014:356131. Doi: $10.1155 / 2014 / 356131$

3 Sun SY, Araujo Júnior E, Elito Júnior J, et al. Diagnosis of heterotopic pregnancy using ultrasound and magnetic resonance imaging in the first trimester of pregnancy: a case report. Case Rep Radiol 2012;2012:317592. Doi: 10.1155/2012/317592

4 Selo-Ojeme DO, GoodFellow CF. Simultaneous intrauterine and ovarian pregnancy following treatment with clomiphene citrate. Arch Gynecol Obstet 2002;266(04):232-234. Doi: 10.1007/s0040 40100213

5 Bugatto F, Quintero-Prado R, Kirk-Grohar J, Melero-Jiménez V, Hervías-Vivancos B, Bartha JL. Heterotopic triplets: tubal ectopic and twin intrauterine pregnancy. A review of obstetric outcomes with a case report. Arch Gynecol Obstet 2010;282(06):601-606. Doi: 10.1007/s00404-010-1577-z

6 Kiely JL, Kiely M. Epidemiological trends in multiple births in the United States, 1971-1998. Twin Res 2001;4(03):131-133. Doi: 10.1375/twin.4.3.131

7 Marshal GB. Case of ruptured tubal gestation associated with twin pregnancy in uterus. J Obstet Gynaecol 1903;4:448-450. Doi: 10.1111/j.1471-0528.1903.tb11815.x

8 Divry V, Hadj S, Bordes A, Genod A, Salle B. Case of progressive intrauterine twin pregnancy after surgical treatment of cornual pregnancy. Fertil Steril 2007;87(01):190.e1-190.e3. Doi: 10.1016/j. fertnstert.2006.04.053

9 Inion I, Gerris J, Joostens M, De Vree B, Kockx M, Verdonk P. An unexpected triplet heterotopic pregnancy after replacement of two embryos. Hum Reprod 1998;13(07):1999-2001. Doi: 10.1093/humrep/13.7.1999

10 Nikolaou DS, Lavery S, Bevan R, Margara R, Trew G. Triplet heterotopic pregnancy with an intrauterine monochorionic diamniotic twin pregnancy and an interstitial pregnancy following in vitro fertilisation and transfer of two embryos. J Obstet Gynaecol 2002;22(01):94-95. Doi: 10.1080/01443610211123

11 Cholkeri-Singh A, LaBarge A. Spontaneous heterotopic triplets: a case report. Fertil Steril 2007;88(04):968.e5-968.e7. Doi: 10.1016/j. fertnstert.2006.12.034

12 Pan HS, Chuang J, Chiu SF, et al. Heterotopic triplet pregnancy: report of a case with bilateral tubal pregnancy and an intrauterine pregnancy. Hum Reprod 2002;17(05):1363-1366. Doi: 10.1093/ humrep/17.5.1363

13 Bataille P, Reynard A, Ducarme G. Spontaneous heterotopic triplets - A review of literature. J Gynecol Obstet Hum Reprod 2017;46(08):657-659. Doi: 10.1016/j.jogoh.2017.05.008

14 Alsunaidi MI. An unexpected spontaneous triplet heterotopic pregnancy. Saudi Med J 2005;26(01):136-138

15 Simsek T, Dogan A, Simsek M, Pestereli E. Heterotopic triplet pregnancy (twin tubal) in a natural cycle with tubal rupture: case report and review of the literature. J Obstet Gynaecol Res 2008;34 (4 Pt 2):759-762. Doi: 10.1111/j.1447-0756.2008.00921.x

16 Jeong HC, Park IH, Yoon YS, et al. Heterotopic triplet pregnancy with bilateral tubal and intrauterine pregnancy after spontaneous conception. Eur J Obstet Gynecol Reprod Biol 2009;142 (02):161-162. Doi: 10.1016/j.ejogrb.2008.10.013

17 Arsala L, Danso D. Spontaneous heterotopic triplet pregnancy with tubal rupture: a case report and literature review. J Investig Med High Impact Case Rep 2014;2(02):2324709614531556. Doi: $10.1177 / 2324709614531556$

18 Nguyen-Tran C, Toy EC. Case 3: obstetrical. Heterotopic pregnancy: viable twin intrauterine pregnancy with a viable right tubal ectopic pregnancy. J Ultrasound Med 2000;19(05):355 